\title{
Thrombocytopenia 2
}

National Cancer Institute

\section{Source}

National Cancer Institute. Thrombocytopenia 2. NCI Thesaurus. Code C129035.

An autosomal dominant disorder caused by mutation(s) in the ANKRD26 gene, encoding ANKRD26 protein. Additionally, in one family, a mutation(s) has been identified in the MAST L gene, encoding serine/threonine-protein kinase greatwall. The condition is characterized by mild to moderate bruisability. 